\title{
CULTURAL HERITAGE, NATURAL RESOURCES AND COMPETITIVENESS OF THE TRAVEL AND TOURISM INDUSTRY IN CENTRAL AND EASTERN EUROPEAN COUNTRIES
}

\author{
Diana Dugulan ${ }^{1}$, \\ Virgil Balaure ${ }^{2}$, \\ Ioana Cecilia Popescu, \\ Călin Vegheş ${ }^{4}$
}

\begin{abstract}
Competitiveness has become one of the common concepts employed in the recent years to approach and describe the sustainable development of the travel and tourism industry. Cultural heritage and natural resources represent two significant pillars of the tourism's sustainable development: that is why the development of the tourism based on the cultural heritage and natural resources could provide a consistent support for increasing the competitiveness of the Central and Eastern European countries as tourist destinations. The paper assesses how important are and what are the contributions of the cultural heritage and natural resources to the overall competitiveness of the travel and tourism industry and to its performances based on specific data referring to the Central and Eastern European countries.
\end{abstract}

Key words: cultural heritage, natural resources, tourism competitiveness, Central and Eastern Europe

JEL codes: L83, M31.

\section{Introduction}

The competitiveness of a the travel and tourism industry represent a complex and, in the same time, a relative concept, a part of this complexity being determined by the definition given to the tourist destinations, seen as places or some form of actual or perceived boundary, such as physical boundaries of an island, political boundaries, or even market-created boundaries (Kotler, Bowen, and Markens, 2006), and the specific methods employed to assess it. Due to the impressive growth in the last decades, with the exception represented by the recent years of the economic downturn, tourism has become one of the fastest growing and still remains one of the largest economic sectors (WTTC 2009).

Tourist destination competitiveness has as support the three pillars of the natural resources, climate and culture (Lumsdon, 1997), to which can be added the existing infrastructure, political stability and currency fluctuation, and some other factors that can decrease the competitiveness, such as violence, natural catastrophes, adverse environment factors and overcrowding (Kotler, Bowen, and Markens, 2006). Other elements to be considered in the analysis of the tourist destinations competitiveness include the geographical location, environmental and physical conditions, demographical situation, existing tourist attractions, image perceived and image associated with the tourist destination, tourism resources - natural, cultural, activities, infrastructure and services (Ejarque 2005). Ability to increase tourism expenditures, to increasingly attract

\footnotetext{
${ }^{1}$ Academy of Economic Studies in Bucharest, balan_diana1@yahoo.com

${ }^{2}$ Romanian-American University.

${ }^{3}$ Academy of Economic Studies in Bucharest, ipopescu@ase.ro

${ }^{4}$ Academy of Economic Studies in Bucharest, c_veghes@yahoo.com 
visitors, to provide tourists with satisfying and memorable experiences in a profitable manner, to contribute to the enhancement of the well-being of destination residents and the preservation of the natural resources for the future generations are other characteristics of the competitive tourist destinations (Brent Richie and Crouch, 2003).

With millions of people engaging in international and domestic travel to experience heritage of general interest or of a more personal nature, the cultural heritage has become the essence of tourism in many tourist destinations worldwide (Dallen, 2006). The increased demand for cultural experiences as well as employing cultural heritage to attract tourists to the various destinations (Bowitz and Ibenholt, 2009) have given an enhanced position to the cultural resources as a pillar of the travel and tourism competitiveness. As a consequence, has been introduced and defined the concept of heritage tourism, defined as a subgroup of tourism in which the main motivation for visiting a site is based on the place's heritage characteristics according to the tourists' perception of their own heritage (Poria, Butler, and Airey, 2001), the heritage tourism being approached as a final stage of the "heritagization" (Poria and Ashworth, 2009).

Together with the cultural heritage, natural resources and climate have been identified among the significant factors, together with the sport, recreation and education facilities, shopping and commercial facilities, infrastructure, and the cost of living (Tang and Rochananond, 1990) determining the attractiveness of a country as a tourist destination and, by extension, the competitiveness of the travel and tourism industry. Forests, soils, water, fisheries, minerals, and energy can be taken into consideration when approaching the natural resources in relationship with the sustainable development of the tourism industry (Lovins, Lovins, and Hawken, 2007; Hart, 2007). In the context of the inherited and fixed ecology versus economy trade-off - benefits of environmental standards versus higher prices and a reduced industrial competitiveness (Porter and Van der Linde, 2008), the environmental worries became more diversified and impacted significantly the tourism industry. Climate change, energy, water, biodiversity and land use, chemicals, toxins, and heavy metals, air pollution, waste management, ozone layer depletion, oceans and fisheries, and deforestation are the top environmental issues affecting the sustainable development of the tourism industry (Esty and Winston, 2006).

As the countries of the Central and Eastern Europe are not uniform but diverse entities in terms of location, topography, climate, history, culture and economic development, each of these will have to identify its own competitive advantage (Hughes and Allen, 2005). Cultural heritage and natural resources could represent important advantages supporting their competitiveness as tourist destinations and the overall competitiveness of their tourism and travel industries.

\section{Methodological Notes}

The main objectives to be reached through the present research approach referred to the assessment of the correlations between the cultural heritage, natural resources and overall competitiveness and performances of the travel and tourism industry and economy and between the determinant factors and the overall competitiveness of the natural resources in the case of the selected CEE countries.

In order to assess the impact of the cultural heritage and natural resources over the travel and tourism competitiveness it was employed a set of data included in The Travel \& Tourism Competitiveness Report 2009 (called further TTC Report 2009) issued by the World Economic Forum in Geneva, Switzerland. Ten countries of the Central and Eastern Europe (CEE) have been selected from an initial list of 22 based on the affiliation to the region and their status as members of the European Union: Bulgaria, Czech Republic, Estonia, Hungary, Latvia, Lithuania, Poland, Romania, Slovakia, and Slovenia.

Variables of the research approach have been the following: 
- overall travel and tourism competitiveness, as expressed by the specific indexes determined according to the methodologies employed for all the 133 investigated countries covered by the TTC Report 2009;

- performances of the travel and tourism industry and economy: GDP and travel and tourism industry and economy, employment in travel and tourism industry and economy, international tourist arrivals and international tourism receipts;

- factors describing the cultural heritage and natural resources competitiveness: number of the World Heritage cultural and natural sites.

Pearson correlation coefficient has been the statistical tool employed to conduct the measurements and produce the aimed results.

\section{Major Findings}

The overall assessment of the travel and tourism competitiveness in the Central and Eastern Europe countries allows drawing the conclusion that there are less significant difference between these countries in terms of their competitiveness: although Czech Republic (with an overall score of 4.86) and Estonia (4.83) appear slightly distanced in the upper part of the hierarchy, all the ten countries form a relatively uniform group (the average score at the level of the group being of 4.41). Regulatory framework seems to be the most supportive dimension of their competitiveness while the business environment and infrastructure and the human, cultural and natural resources exert an apparently unfavorable impact over the competitiveness of these countries.

Table no. 1.

Natural resources and the travel and tourism industry, economy and performances in the selected CEE countries (2009)

\begin{tabular}{|l|c|c|c|c|c|c|c|c|c|c|c|}
\hline \multicolumn{1}{|c|}{ Countries } & TTC & CH & NR & HS & NS & GDPi & EMPi & GDPe & EMPe & ITA & ITR \\
\hline Czech Rep. & $\mathbf{4 . 8 6}$ & $\mathbf{5 . 4 1}$ & $\mathbf{2 . 8 9}$ & 13 & 0 & 3607 & 98.9 & 20664 & 5002 & 93363 & 6618 \\
\hline Estonia & $\mathbf{4 . 8 3}$ & $\mathbf{2 . 2 6}$ & $\mathbf{3 . 8 3}$ & 4 & 0 & 620 & 17.3 & 2926 & 79 & 4304.8 & 1035 \\
\hline Slovenia & $\mathbf{4 . 5 3}$ & $\mathbf{2 . 6 8}$ & $\mathbf{2 . 9 8}$ & 0 & 1 & 1380 & 32.8 & 6261 & 125 & 54439 & 2483 \\
\hline Hungary & $\mathbf{4 . 4 5}$ & $\mathbf{3 . 9 2}$ & $\mathbf{2 . 6 0}$ & 7 & 1 & 3755 & 180.5 & 9275 & 261 & 39125 & 4728 \\
\hline Slovakia & $\mathbf{4 . 3 4}$ & $\mathbf{2 . 6 9}$ & $\mathbf{3 . 7 3}$ & 6 & 2 & 1459 & 38 & 9402 & 223 & 32905 & 2013 \\
\hline Latvia & $\mathbf{4 . 3 1}$ & $\mathbf{2 . 1 1}$ & $\mathbf{3 . 0 0}$ & 3 & 0 & 425 & 13.4 & 1803 & 56 & 4489 & 671 \\
\hline Lithuania & $\mathbf{4 . 3 0}$ & $\mathbf{2 . 3 9}$ & $\mathbf{2 . 4 9}$ & 6 & 0 & 432 & 12.8 & 2156 & 63 & 4625 & 1153 \\
\hline Bulgaria & $\mathbf{4 . 3 0}$ & $\mathbf{3 . 1 3}$ & $\mathbf{3 . 1 1}$ & 8 & 2 & 1478 & 89.2 & 5629 & 336 & 8204 & 3130 \\
\hline Poland & $\mathbf{4 . 1 8}$ & $\mathbf{5 . 0 8}$ & $\mathbf{3 . 5 3}$ & 12 & 1 & 7157 & 265 & 32040 & 1100 & 58613 & 10627 \\
\hline Romania & $\mathbf{4 . 0 4}$ & $\mathbf{2 . 8 5}$ & $\mathbf{2 . 8 7}$ & 7 & 1 & 3073 & 272.8 & 8289 & 544 & 5273 & 1464 \\
\hline
\end{tabular}

Notes: TTC - Travel and Tourism Competitiveness Index; $\mathrm{CH}-$ Cultural Heritage competitiveness index; NR - Natural Resources competitiveness index; HS - number of the World Heritage cultural sites; NS - number of the World Heritage natural sites; GDPi - GDP and travel and tourism industry (US\$ millions, 2009); EMPi - employment and travel and tourism industry (thousand jobs, 2009); GDPe - GDP and travel and tourism economy (US\$ millions, 2009); EMPe - employment and travel and tourism economy (thousand jobs, 2009); ITA - international tourist arrivals (thousands, 2009); ITR - international tourism receipts (US\$ millions, 2008); countries ranked in the descending order of the TTC index.

Cultural heritage does not appear as a supporting pillar for the travel and tourism competitiveness in the countries of the Central and Eastern Europe $(r=0.18)$ due not necessarily to a lack of these resources but rather to an insufficient or ineffective promotion. Impact of the cultural heritage upon the competitiveness of the travel and tourism industry in the considered countries has been assessed considering the scores expressing the competitiveness of the cultural heritage and the performances in terms of the gross domestic product and employment (for the industry and for the economy), international visitor arrivals and receipts at the level of the ten countries (see Table 1). 
Measurement of the association between the indicators expressing the performances of the travel and tourism industry and economy and the scores expressing the competitiveness of the cultural resources in the considered countries shows strong relationships between these variables, in the cases of all the variables: the gross domestic product and travel and tourism economy $(r=0.90)$, gross domestic product and travel and tourism industry $(\mathrm{r}=0.85)$ and employment and travel and tourism economy $(r=0.77)$, respectively a moderate relationship in the case of the employment and travel and tourism industry $(\mathrm{r}=0.57)$.

Based on these results, it can be concluded that a more effective promotion and employment of the cultural resources available in the considered countries could determine a growth both in terms of the gross domestic product generated by the travel and tourism industry and economy and the number of new direct or indirect workplaces created.

Association between the number of the international visitor arrivals and the international tourism receipts and the competitiveness of the cultural resources in the considered countries shows very strong relationships between these variables $(r=0.83$, respectively $r=0.92)$. These results provide a supplementary support of the idea that specific efforts should be made by the considered countries to preserve, promote and employ their cultural resources.

According to the Travel and Tourism Competitiveness Report, number of UNESCO cultural World Heritage sites is one of the variables describing the content of the cultural resources pillar. The analysis of the relationships between the number of the World Heritage cultural sites and the macroeconomic performances of the travel and tourism industry in the considered countries, allow the observation of the following results:

- there is a strong correlation between the number of the World Heritage cultural sites and the gross domestic product generated at the level of the travel and tourism economy $(r=$ $0.77)$ and industry $(r=0.72)$; registering an increased number of cultural sites on the list of the World Heritage sites, accompanied by an appropriate promotion, will contribute to the increase of the weight in the gross domestic product created by the travel and tourism industry;

- there is a moderate $(\mathrm{r}=0.57)$, respectively a strong $(\mathrm{r}=0.77)$ correlation between the number of the World Heritage cultural sites and the employment in the travel and tourism industry, respectively economy; again, an increased number of cultural sites registered in the World Heritage list, properly promoted and made available will contribute to the creation of new workplaces both direct, within the industry, and indirect in connected activities and industries;

- finally, there is a rather moderate correlation between the international visitor arrivals ( $\mathrm{r}$ $=0.49$ ), respectively a strong correlation between the international tourism receipts and and the number of the registered World Heritage sites in the considered countries $(\mathrm{r}=$ 0.76); these results support the necessity to conduct marketing campaigns to promote them appropriately and to benefit from their extended cultural heritage.

Impact of the natural resources on the competitiveness of the travel and tourism industry in the CEE countries has been assessed considering the scores expressing the competitiveness of the natural resources and the performances in terms of the gross domestic product and employment (for the industry and for the economy), international tourist arrivals and receipts at the level of the ten CEE countries.

Extremely surprisingly, natural resources (assessed through the number of UNESCO natural World Heritage sites) appear to be very poorly related to the competitiveness of the CEE countries as travel and tourism destinations $(\mathrm{r}=0.18)$. This may suggest that although these countries have several natural attractions their contribution to the overall competitiveness of the travel and tourism industry and activities at their level is rather less significant. Also, CEE countries seem to 
unfortunately not have the knowledge and/or found the capacities for an effective employment of the natural resources as a critical driver of their competitiveness.

Measurement of the association between the indicators expressing the performances of the travel and tourism industry and economy and the scores expressing the competitiveness of the natural resources in the CEE countries shows rather poor relationships between these variables in the cases of the gross domestic product and travel and tourism economy $(\mathrm{r}=0.27)$, and employment and travel and tourism economy $(\mathrm{r}=0.22)$, respectively very poor relationships in the case of the employment and travel and tourism industry $(\mathrm{r}=-0.11)$ and gross domestic product and travel and tourism industry $(\mathrm{r}=0.07)$.

A more effective employment of the natural resources available in the CEE countries seems to not determine a significant improvement in terms of the macroeconomic performances generated by the travel and tourism industry and economy (gross domestic product growth and/or a higher number of newly created workplaces). Or, in other words, CEE countries should orientate their efforts, on a shorter-term perspective, toward the improvement of the business environment and infrastructure, respectively the regulatory framework as these appear to be the major determinants of their overall travel and tourism competitiveness.

Association between the number of the international tourist arrivals and the international tourism receipts and the scores expressing the competitiveness of the natural resources in the CEE countries shows also a very poor relationship between these variables $(\mathrm{r}=0.06$, respectively $\mathrm{r}=0.11)$. These results may suggest the necessity for these countries to expand the specific efforts of preserving, promoting and taking advantage of their available natural resources. In spite of the less significant present, these resources should become one, considering a medium or a long-term horizon, one of the most important motivators of the international tourists in their selection of the CEE countries as destinations for the travel and holidays to be made.

Assessment of the correlation between the number of UNESCO natural World Heritage sites and the overall competitiveness of the travel and tourism industry in the CEE countries indicate, surprisingly, that there is a moderate and inverse correlation between the overall competitiveness and the number of the World Heritage natural sites in the investigated CEE countries $(r=-0.45)$; apparently, a lower number of the natural sites registered by UNESCO (at least by comparison to other tourist destinations worldwide) should transform these countries in more attractive destinations for the international tourists, generate higher receipts (and revenues) and influencing in a favorable manner the overall competitiveness of the travel and tourism industry.

\section{Conclusions}

Although their overall scores vary around the determined average value, the investigated group of CEE countries form a relatively uniform assembly in terms of their travel and tourism competitiveness characterized through a higher attention given to the appropriateness of the business environment and infrastructure and the regulatory framework and a less concern for capitalize the existing natural heritage. The overall scores registered by these countries according to the TTC Report 2009, place them in the middle area of the hierarchy built in terms of the travel and tourism competitiveness.

Cultural resources contribute, surprisingly, in a very poor measure to the overall competitiveness of the considered countries seen as travel and tourism destinations. Knowledge and capacities for an effective employment of the cultural resources become essential for these countries in their attempts to transform these in critical drivers of their travel and tourism competitiveness.

Focus on particular capitalization of the existing cultural heritage appears to be critical as the relationships between the competitiveness of the cultural resources and the macroeconomic performances of the travel and tourism industry in the considered countries reveal a strong 
association. A more effective promotion and employment of the cultural resources would determine a growth in terms of the GDP generated and of the number of workplaces created by the travel and tourism industry of these countries. Taking advantage of the available cultural resources, inclusively through the development of the heritage tourism, should be reflected in the specific industry's performances as an increased competitiveness of these resources could determine significant increases in the number of the international visitor arrivals and of the international tourism receipts.

Natural resources are also very poorly related to the overall competitiveness of the CEE countries seen as travel and tourism destinations although it would have been expected a more consistent contribution in this respect. Again, knowledge as well as the capacities for an effective employment of the natural resources become both essential for the CEE countries in their attempts to transform this category of resources in a key driver of their travel and tourism competitiveness.

A lower number of the natural sites registered by UNESCO in the World Heritage, and a lower number of known species (at least by comparison to other tourist destinations worldwide), as well as an expanded surface of the protected areas and an overall better quality of the natural environment should transform these countries in more attractive destinations for the international tourists, generate consequently higher receipts and revenues, and exerting a favorable influence over the competitiveness of the travel and tourism industry.

\section{References}

1. Blanke, J., Chiesa, T. (editors), 2009. The Travel \& Tourism Competitiveness Report 2009. Managing in a Time of Turbulence, World Economic Forum Geneva, Switzerland 2009, available at http://www.weforum.org/pdf/TTCR09/TTCR09_FullReport.pdf

2. Bowitz, E., Ibenholt, K., 2009. Economic impacts of cultural heritage e Research and perspectives, Journal of Cultural Heritage, Vol. 10, pp. 1-8.

3. Brent Ritchie, J.R., Crouch, G.I., 2003. The Competitive Destination: A Sustainable Tourism Perspective, Cabi Publishing.

4. Dallen, T. J., 1996. Tourism and the Personal Heritage Experience, Research Notes and Reports, pp.751-754.

5. Ejarque, J., 2005. Destinos turísticos de éxito. Diseño, creación, gestión y marketing, Madrid, Ediciones Piramide

6. Esty, D.C., Winston A. S., 2006. Green to Gold, Yale University Press New Haven and London.

7. Hart, S.L., 2007. Beyound Greening: Strategies for a Sustainable World, Harvard Business Review on Green Business Strategy, Harvard Business School Press

8. Hughes, H., Allen, D., 2005. Cultural tourism in Central and Eastern Europe: the views of

1. 'induced image formation agents', Tourism Management, Vol. 26, pp. 173-183.

9. Kotler, Ph., Bowen, J.T., Markens, J.C., 2006. Marketing for Hospitality and Tourism, New Jersey, Pearson Prentice Hall International Edition

10. Lumsdon, L., 1997. Tourism marketing, London, International Thomson Business Press

11. Lovins, A.B., Hunter Lovins, L., Hawken, P., 2007. A road Map for Natural Capitalism, Harvard Business Review on Green Business Strategy, Harvard Business School Press

12. Porter, M.E., Van Der Linde, C., 2008. Green and Competitive: Ending the Stalemate, Harvard Business Review on Prifiting from Green Business, Harvard Business Press

13. Poria, Y., Ashworth, G., 2009. Heritage Tourism-Current Resource for Conflict, Annals of Tourism Research, Vol. 36, No. 3, pp. 522-525.

14. Poria, Y., Butler, R., Airey, D, 2001. Clarifying Heritage Tourism, Annals of Tourism Research, Vol. 28, No. 4, pp. 1047-1049.

15. Tang, J.C.S, Rochananond, N., 1990. Attractiveness as a Tourist Destination: A 
Comparative Study of Thailand and Selected Countries, Socio-Economic Planning Science, Vol. 24, No. 3, pp. 229-236. 